\title{
Peripheral edema with pregabalin
}

\section{Romayne Gallagher MD, Nicole Apostle MD}

\section{Competing interests: Romayne Gallagher has received honoraria from Purdue Pharma. No other competing interests were declared.}

This article has been peer reviewed.

Affiliation: From the Palliative Care Program (Gallagher, Apostle), Providence Health Care, Vancouver, BC

Correspondence to: Romayne Gallagher, rgallagher@providencehealth .bc.ca

CMAJ 2013. DOI:10.1503 /cmaj.121232

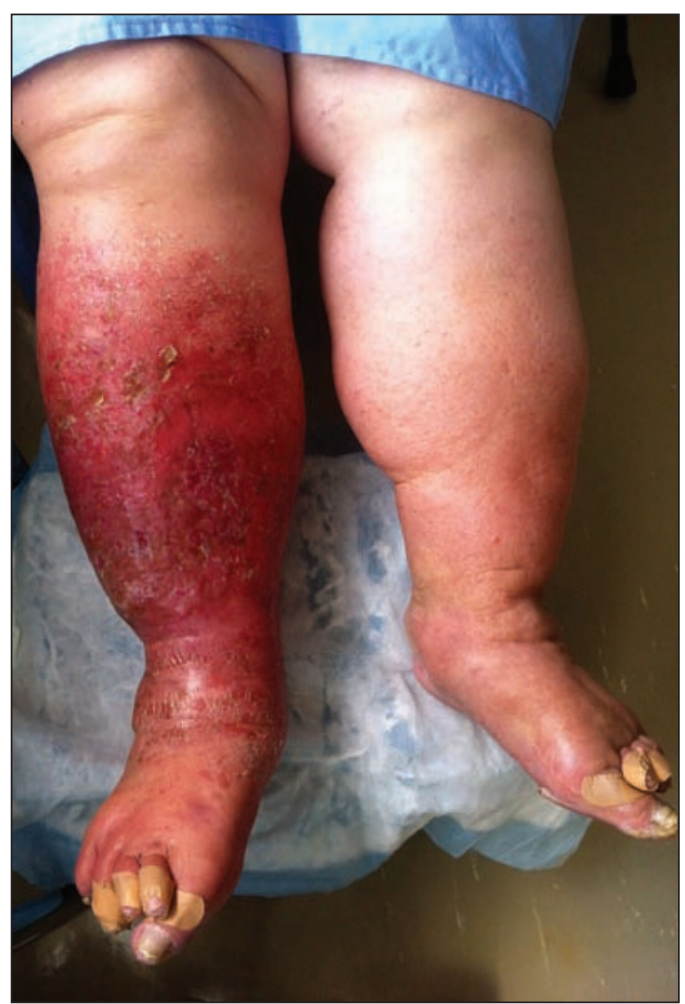

Figure 1: Peripheral edema in a 76-year-old woman taking pregabalin for neuropathic pain.

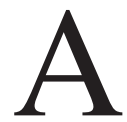
76-year-old woman with a 20 -year history of chronic pain in her back and legs caused by degenerative spondylolisthesis, spinal stenosis, morbid obesity, venous insufficiency and osteoarthritis presented to our chronic pain clinic. She had previously undergone a laminectomy at L4-L5/L5-S1 and, 2 years later, an L1-S1 decompression and fusion.

In 2008, after the decompression surgery, the patient was given pregabalin (titrated to $300 \mathrm{mg}$, twice daily) for ongoing neuropathic pain. Increasing peripheral edema in the patient's legs was documented from that time on. In 2011, chronic wounds with serous drainage developed on the patient's legs. In early 2012, the patient spent 53 days in hospital with a diagnosis of cellulitis, and she was no longer independently mobile. Investigations ruled out deep venous thrombosis, liver dysfunction and malnutrition.

The patient was admitted to hospital because of poor pain control, chronically weeping leg wounds and poor mobility. The edema was more severe in her right leg, with the calf measuring $57 \mathrm{~cm}$ in circumference (Figure 1). We decreased the patient's pregabalin dose and stopped its use within 1 week of admission. By the 10th day of the patient's stay, the circumference of each calf had decreased by $10 \mathrm{~cm}$, and the wounds on her right leg were healing and no longer weeping (Appendix 1, available at www.cmaj.ca/lookup/suppl/doi:10.1503/cmaj .121232/-/DC1).

Pregabalin is used to treat neuropathic pain. The drug's likely mechanism of action is binding to the $\alpha_{2} \delta$ subunits of voltage-gated calcium channels in presynaptic neurons, thereby reducing the release of the excitatory neurotransmitter glutamate.

In older adults, common adverse effects of pregabalin include dizziness $(34 \%)$ and drowsiness $(22 \%) .{ }^{1}$ Peripheral edema $(15 \%)^{1}$ and worsening of heart failure symptoms have also been reported. ${ }^{2,3}$ These effects may be the result of antagonism of the L-type calcium channel in the vasculature causing vasodilatation, similar to the mechanism of action of calcium channel blockers used to treat hypertension.

Peripheral edema may go unrecognized as an adverse effect of pregabalin, leading to loss of mobility and a prolonged stay in hospital as in the case of our patient.

\section{References}

1. Semel D, Murphy TK, Zlateva G, et al. Evaluation of the safety and efficacy of pregabalin in older patients with neuropathic pain: results from a pooled analysis of 11 clinical studies. $B M C$ Fam Pract 2010;11:85.

2. Page RL II, Cantu M, Lindenfeld J, et al. Possible heart failure exacerbation associated with pregabalin: case discussion and literature review. J Cardiovasc Med (Hagerstown) 2008;9:922-5.

3. Toth C. Drug safety evaluation of pregabalin. Expert Opin Drug Saf 2012;11:487-502. 